\title{
Revista \\ Triângulo \\ OS DESAFIOS PARA A FORMAÇÃO DE PROFESSORES DO ENSINO SUPERIOR
}

\author{
THE CHALLENGES FOR TEACHER TRAINING OF HIGHER EDUCATION
}

\author{
Marcos T. Masetto ${ }^{1}$ \\ Cecilia Gaeta ${ }^{2}$
}

\begin{abstract}
RESUMO
A Educação Universitária no Brasil vem mudando consideravelmente nas últimas décadas influenciado principalmente por dois fatores: a expansão e democratização desse nível de ensino que aumentou consideravelmente o numero e as características dos alunos na faculdade; e, o enfrentamento dos efeitos e consequências das tecnologias da informação e comunicação sobre as áreas do conhecimento, aprendizagem e formação de profissionais. No cenário que se apresenta é estratégica a atuação competente do professor para formar os alunos na "nova universidade". A expectativa é que o docente atue com profissionalidade, o que consequentemente exige um processo de formação específico. Os autores desse trabalho vêm estudando e trabalhando com a formação de professores universitários há várias décadas e propõem como objetivo desse trabalho: Compartilhar reflexões sobre os desafios na formação do professor do ensino superior no cenário brasileiro e apresentar uma experiência diferenciada. A metodologia utilizada de caráter qualitativo esta baseada em estudos bibliográfico principalmente dos autores Bain (2004), Imbernon (1998), Masetto (2012) Perrenoud (2000) Torre (2008), Zabalza (2006) e na analise documental pesquisa experimental de Gaeta (2007). Ao final, os autores reafirmam a profissionalidade docente como uma das respostas possíveis aos atuais desafios da docência e ressaltam a importância de se criar oportunidades e espaços de formação de professores que desenvolvam competências didático-pedagógicas.
\end{abstract}

Palavras-chave: Educação superior. Formação de professores. Professor universitário.

\begin{abstract}
The Higher Education in Brazil has changed considerably in recent decades mainly influenced by two factors: the expansion and democratization of this level of education which greatly increased the number and characteristics of students in the university and college, and the challenge of facing the effects of new technologies on areas like knowledge, learning and training professionals. In this scenario the competent work of teacher to train students in the "new university" is strategic. The expectation is that teachers act with professionalism, which in turn requires a specific training process. The authors of this article have been studying and working with teachers and their development process for years, they have a lot of experience, so they propose the following objective for this paper: share their reflections about the challenges to train teachers of higher education and describe a differentiated experience. We used a qualitative methodology literature, mainly based on studies of the authors Bain (2004), Imbernon (1998), Masetto (2012) Perrenoud (2000) Torre (2008), Zabalza (2004, 2006). Is also supported by the documentary analysis of experimental research of Gaeta (2007) At the end, the authors reaffirm the teaching profession as one of the possible answers to the current challenges and highlight the importance of creating opportunities and spaces for pedagogical development of teachers in universities.
\end{abstract}

Key-words: Higher education in Brazil. Training teachers. Professor.

1 Professor titular da Pontifícia Universidade Católica de São Paulo - PUC-SP. Email:mmasetto@gmail.com

2 Pesquisadora independente do Grupo de pesquisa FORPEC da PUC-SP. E-mail: ceciliagaeta@uol.com.br 


\section{Introdução}

O ensino superior brasileiro vem sendo afetado significativamente por dois fenômenos. O primeiro são as politicas de expansão e democratização com grandes investimentos públicos e privados em vagas, em polos universitários e em políticas de acesso. Um plano de metas educacionais foi estabelecido no ano $2000 \mathrm{com}$ a proposta de aumentar de $10 \%$ para $30 \%$ o numero de jovens entre 18 e 24 anos cursando a faculdade até o ano de 2020. Desde então, aumentamos três vezes o numero de matrículas e em $110 \%$ o numero de alunos no ensino superior. ${ }^{3}$ As classes se tornaram numerosas e heterogêneas. Muitos professores foram contratados para atender a nova demanda. Em 2006 o censo apontava 242.795 professores e em 2011 já éramos $345.335^{4}$.

O segundo fenômeno que atinge o ensino superior brasileiro diz respeito ao impacto das tecnologias de informação e comunicação sobre as áreas do conhecimento, da aprendizagem e da formação de profissionais. As fontes de produção se multiplicam exigindo abertura de diálogo com a universidade, o acesso às informações abre-se a todos e o professor deixa de ser a única fonte de informação para seus alunos. Na aprendizagem, resgata-se o conceito complexo de que aprender no ensino superior envolve o desenvolvimento do aluno nos aspectos cognitivo, afetivo emocional, das habilidades e das atitudes e valores. Há a valorização da aprendizagem significativa, colaborativa e ao longo da vida. A formação dos alunos considera o surgimento de novas profissões, a fusão de outras e os avanços tecnológicos.

Nas circunstâncias descritas acima, de mudanças profundas da universidade, os professores vivem desafios e problemas decorrentes do novo contexto e procuram caminhos para uma docência diferenciada. As exigências de qualificação para a contratação dos professores nas universidades praticamente se limitam à formação na pósgraduação que, por se caracterizar por estudos para a formação do pesquisador, se mostrou insuficiente para enfrentar os desafios que os processos de ensinar e aprender atual exigem. Muitas dificuldades surgem, é preciso principalmente reaprender a ser professor. Nossa

\footnotetext{
3 Veja Censo Educação Superior de 2011 http://portal.inep.gov.br/superior-censosuperior. Acesso em $11 / 11 / 2013$.

${ }^{4}$ http://portal.inep.gov.br/superior-censosuperior. Acesso em 11/11/2013.
} 
experiência tem nos permitido conviver com colegas nessa situação aflitiva e tem nos proporcionado oportunidades de colaborar nesse processo. Nesse sentido esse texto propõe o seguinte objetivo: compartilhar reflexões sobre os desafios na formação do professor do ensino superior no cenário da educação brasileira e apresentar uma experiência de formação docente.

\section{Metodologia}

Em nossa vivência temos estudado, pesquisado, publicado para discutir nossas investigações e conclusões ${ }^{5}$, criado cursos de diversas naturezas, formado grupos de trabalho entre outras atividades para compartilhar nossas reflexões sobre a formação de professores para a docência universitária. Desenvolvemos também um curso de Pósgraduação, especialização em Docência no ensino superior, para professores do ensino superior que está apresentado nesse trabalho. Toda essa experiência alicerça nossa pesquisa e nos dá base para escrever esse texto. Podemos então considerar a metodologia utilizada de caráter qualitativo apoiada em pesquisa bibliográfica onde se destacam os seguintes autores: Bain (2004), Imbernon (1998), Masetto (2012) Perrenoud (2000) Torre (2008), Zabalza $(2004,2006)$ e na analise documental dos resultados da pesquisa experimental de Gaeta (2007). O texto esta construído da seguinte maneira: 1) Partilhamos nossas reflexões, estudos pesquisas e publicações sobre os desafios que se apresentam para a formação de professores no contexto do ensino superior brasileiro. 2) Relatamos uma experiência diferenciada de formação de professores universitários para o enfrentamento desses desafios, que se transformou em uma tese de doutoramento.

\section{Desafios para a formação do professor do ensino superior no Brasil}

A partir de nossas pesquisas e debates sobre a formação didático-pedagógica dos professores universitários, fundamentados nos autores acima indicados, selecionamos cinco desafios que se mostraram os mais marcantes a serem enfrentados.

\footnotetext{
${ }^{5}$ Masetto (1998, 2000, 2003, 2007, 2009, 2010, 2012, 2013); Gaeta (2002, 2007, 2012, 2013).
} 


\subsection{Desafio cultural}

A maioria dos docentes do ensino superior que hoje atuam em nossas faculdades se formou a partir de currículos estruturados no modelo francês-napoleônico de universidade, onde o papel do professor é central, chamando para si a responsabilidade de, como um especialista, dominar uma área do conhecimento e de práticas profissionais e transmiti-las aos seus alunos. Diante disso, o desafio que encontramos é mudar a cultura desse professor para que ele valorize o aluno como sujeito da construção de seu conhecimento, desenvolvendo suas habilidades de pesquisar, buscar, analisar, sistematizar informações, socializa-las e finalmente integrá-las a seu mundo intelectual O professor deixa de ser o centro da aula e da informação para ocupar um papel de incentivador do aluno na atitude de pesquisar e construir seu conhecimento. O professor torna-se um mediador entre o aluno e sua aprendizagem. Trata-se de uma mudança cultural radical no papel do professor. (MASETTO, 2012)

1.2. Desafio de uma docência com profissionalidade.

No cenário atual, a docência no ensino superior assume uma dimensão de profissionalidade. E o desafio está em trabalhar com o professor para que ele assuma essa sua nova profissão, que entenda que assim como ele se preparou durante vários anos para exercer sua profissão de médico, economista, e demais profissões, agora ele precisa aprender a atuar como professor de forma profissional. $O$ que pressupõe $o$ desenvolvimento de competências específicas, e por decorrência exige também uma formação adequada. Não mais é suficiente ter um diploma e "dar aulas" é preciso "ser professor e desenvolver a aprendizagem". (GAETA e MASETTO, 2013a)

\subsection{Desafios de Competências}

Posto que a docência exige competências próprias, o desafio para o professor é reconhecer e ampliar a abrangência de sua aptidões, desenvolvendo: 
Competência na área do conhecimento, que compreende além de domínio uma área específica, um trabalho constante de atualização, aprofundamento e sistematização desse conhecimento a partir da pesquisa, abrindo-se para a interdisciplinaridade e integração entre áreas. Pesquisar no sentido de construir conhecimento e contribuir intelectualmente com e para sua área profissional. (MASETTO, 2012)

Competência na área pedagógica que lhe permita: (i) compreender o processo de aprendizagem de adultos em sua complexidade e orientar o aluno a desenvolvê-lo; (ii) relacionar sua disciplina com as demais do curso de modo a colaborar para a formação integral do egresso; (iii) planejar adequadamente sua disciplina, com objetivos claros, com os temas e conteúdos selecionados a partir dos objetivos; com utilização de metodologias ativas que incentivem o aluno a aprender, os tornem participantes nas atividades em classe e extra classe que lhes permita assumir a responsabilidade pelo seu processo de aprendizagem; rever o processo de avaliação de forma a integra-lo ao processo de aprendizagem, fornecendo continuas informações que permita ao aluno corrigir os erros em direção à formação esperada; (iv) criar com seus alunos uma relação de parceria, corresponsabilidade, diálogo, confiança e trabalho em equipe; (v) fazer uso da mediação pedagógica. (GAETA e MASETTO, 2013b, BAIN, 2004, TORRE, 2008, ZABALZA, 2006)

Competência na dimensão política. Espera-se da formação profissional atual que sejam desenvolvidas também nos alunos as dimensões: ética, política, econômica, de responsabilidade social e de cidadania. Não como uma disciplina isolada, mas, no contexto de cada assunto a ser trabalhado. Consequentemente o professor precisa abordar esses aspectos em suas atividades, relacionando-os e incluindo-os nos estudos e debates dos temas profissionais, para que o aluno possa analisar sua profissão sob os aspectos da cidadania. (MASETTO, 2012)

\subsection{Desafios quanto à formação profissional e Projeto Pedagógico}

A formação de qualquer profissional durante seu curso universitário depende do conjunto das disciplinas e atividades integradas num currículo, que se materializam no Projeto Pedagógico do Curso. E aí se apresenta um grande desafio para o professor: acostumado a ser responsável pela sua disciplina isoladamente, agora precisa compreender 
e integrar seu planejamento didático ao projeto pedagógico. Nesse documento constará as expectativas institucionais sobre o egresso, os objetivos de formação do profissional, a organização dos conteúdos, das disciplinas e das práticas profissionais de forma integrada, a proposição de metodologias e procedimentos de avaliação. Ou seja, nele encontrará os parâmetros sobre os quais deverá compor sua disciplina para integra-la ao curso e contribuir para a formação geral do aluno.

1.5. Desafio de planejar uma formação dos docentes para enfrentar estes desafios

A formação de docentes do ensino superior para superar estes desafios exige projetos que lhes permitam estudar e discutir propostas e alternativas teóricas e práticas, refletir sobre sua ação docente integrando-a ao novo no cenário, assumir nova atuação em suas aulas. No Brasil, a Pós Graduação Stricto Sensu não atende a esse propósito porque está direcionada para a formação do pesquisador. Já os cursos de Especialização ou também denominados Pós Graduação Lato Sensu têm objetivos prático-profissionais específicos destinados ao aperfeiçoamento nas partes de que se compõe um ramo profissional ou científico. (GAETA 2007)

No entanto, nossos estudos apontam que os cursos de Especialização apresentam algumas caraterísticas, próprias da educação continuada que poderiam se configurar como espaço propício para a formação de professores no enfrentamento dos desafios descritos: oferece oportunidade para debater a prática, trocar experiências que tenham significado e aplicabilidade imediata e discutir o dia a dia da sala de aula. Educação continuada entendida como forma de aprimoramento, atualização e aperfeiçoamento da atuação docente. (IMBERNÓN, 1998), (PERRENOUD, 2000).

Nessa perspectiva, planejamos e implantamos o curso que apresentaremos a seguir.

\section{Curso de formação de professores do ensino superior}

Este projeto foi criado, planejado e implementado por uma equipe interdisciplinar de professores, reunindo docentes das áreas de Educação e de Turismo com a coordenação 
da Profa. Cecilia Gaeta. Vem funcionando há 12 anos e se constituiu na tese de doutoramento de Gaeta, defendida em 2007. Com um currículo em constante aprimoramento hoje apresenta a configuração apresentada abaixo e atende a profissionais de todas as áreas de conhecimento, não apenas os de turismo. Desenvolve-se em 360 horas durante um ano nas modalidades presencial e EAD. Sua concepção parte do entendimento de que para uma competente e responsável atuação, os professores devem refletir sobre as várias dimensões do processo de "tornar-se professor": a cognitiva (os saberes específicos de sua área de atuação); pedagógica (didática adequada ao ensino superior), reflexiva (a capacidade de pesquisar sobre sua própria prática apoiada por referenciais teóricos) e a política (formação da identidade profissional docente). A estrutura curricular contempla, em ambientes presenciais e virtuais, três grupos de componentes que desenvolvem (i) Fundamentação- são os componentes que desenvolvem conceitos e princípios básicos da educação superior; (ii) Profisssionalização: são os componentes que desenvolvem reflexão sobre o papel atual do professor do ensino superior; (iii) Atuação docente: são os componentes didático pedagógicos próprios para a docência profissional no ensino superior.

Estabelecemos o seguinte alicerce de conhecimentos:

1. Educação superior: em seus fundamentos, história e contexto atual; em suas políticas públicas e diretrizes curriculares, na compreensão do processo de aprendizagem do adulto, no conhecimento e domínio da metodologia adequada para incentivar e favorecer a aprendizagem, no repensar o processo de avaliação, no planejamento da aprendizagem em suas versões presenciais e à distância

2. Desenvolvimento profissional do professor com as questões relativas a tornar-se professor do ensino superior, o papel do professor na realidade atual, as representações e significados sociais, suas necessidades de desenvolvimento profissional e relações interpessoais com colegas, alunos e instituição,

3. Pesquisa: foram incluídos atividades e projetos de pesquisa, tradicionais e interdisciplinares buscando o desenvolvimento e valorização da pesquisa bem como da habilidade de construí-la, na perspectiva de formação do professor-pesquisador que reflete sobre sua própria prática e desenvolve conhecimento novo e atual e de atualização de conteúdos nas áreas específicas de conhecimento. 
4. Novas tecnologias, com ênfase na EAD e sua utilização no ensino superior. Os processos e ensino-aprendizagem podem incorporar e incrementar suas ações aproveitando-se das vantagens que as novas técnicas proporcionam. O professor deve conhecer e saber aplicar adequadamente novas metodologias.

Definimos como público-alvo: Graduados no ensino superior que queiram ingressar na docência para o ensino superior, ou professores que já atuam que queiram aperfeiçoar ou atualizar suas competências. Ou seja, encontramos na mesma sala, futuros professores de diferentes áreas de estudos.

Adotamos como proposta metodológica a interação entre a área de educação e as áreas específicas de estudos de cada aluno, de modo que este possa desenvolver competências na docência da área em que já tenha aderência. Por exemplo, o aluno de Turismo, refletirá sobre o ser professor a partir das peculiaridades do Turismo, o de Administração a partir dos princípios da Administração, e assim por diante.

Está também prevista a integração contínua e dinâmica entre todas as atividades individuais e colaborativas em ambientes presenciais e virtuais. $\mathrm{O}$ curso inicia-se com os alunos selecionando um tema de sua área sobre o qual pretende se especializar como professor. Esse tema passa a ser transversal ao curso, tornando-se a base para as demais atividades que serão desenvolvidas: reflexão sobre ser professor do ensino superior, pesquisa de aprofundamento de conteúdo, planejamento de atividades interdisciplinares, desenvolvimento de um plano de ensino, prática docente, entre outras, seja em ambientes presenciais seja em ambientes virtuais.

As atividades vão se sucedendo conforme os objetivos propostos rompendo com a linearidade tradicional e proporcionando aos alunos que alternem seu papel ao longo do curso: como aprendizes da docência atualizando, aprofundando ou desenvolvendo conhecimentos e competências; e como professores em exercício, aplicando em situações práticas sua aprendizagem. A avaliação adotada é formativa, portanto é mais uma oportunidade de reflexão de professores e alunos sobre os processos de aprender: a auto avaliação é constantemente estimulada. (GIL, 2007)

O curso tem sido ofertado desde 2002 ininterruptamente na forma presencial e a partir de 2010 também em EAD. Os resultados têm sido muito gratificantes, tendo atingido e alterado a concepção do que é ser professor do ensino superior de mais de 700 alunos. 


\section{Considerações finais}

Ser professor universitário no Brasil atualmente tem se tornado uma tarefa cada vez mais complexa, exigente e desafiadora. Complexa porque abrange várias facetas e dimensões da pratica docente para corresponder as diferentes expectativas criadas pelo ambiente educacional moderno e transformador. Desafiadora porque se vive um momento de incerteza própria dos rompimentos de paradigmas: já não basta "dar aulas" para ser professor é preciso ser profissional da docência.

Assumir a docência no Ensino Superior com profissionalidade é a exigência que a sociedade hoje faz na esperança de ver encaminhadas soluções novas e construtivas para seus problemas atuais na busca de formação de profissionais que respondam às necessidades da sociedade com competência e cidadania.

A reconstrução do que é ser professor da universidade exige competências didáticopedagógica específicas que precisam ser desenvolvidas. São necessários subsídios, incentivos e condições para que os professores percebam o fazer docente com outras perspectivas. Precisam aprender a analisar o contexto educativo em que se encontram e então, revisar e, se necessário, transformar suas práticas em busca de melhores resultados de aprendizagem e de formação dos profisssionais.

Nem sempre se encontram ambientes e espaços propícios para o processo de formação docente e os professores muitas vezes ficam entregues à própria sorte no enfrentamento de tantos e tão desconhecidos desafios. Nossa intenção nesse trabalho foi partilhar um pouco de nossa experiência e abrir perspectivas de reflexão e respostas a algumas dessas preocupações.

\section{Referências}

BAIN, Ken. Lo que hacen lós mejores profesores universitários. Valencia, Espanha: Ed. Universitat de Valencia, 2004.

GAETA, Cecilia. Formação docente para o ensino superior: uma inovação em cursos de especialização. Tese apresentada à Pontifícia Universidade Católica de São Paulo, Programa de pós-graduação Educação - Currículo. São Paulo, Brazil, 2007. 
; MASETTO, Marcos. O professor Iniciante no ensino superior: aprender, atuar e inovar. São Paulo: Editora Senac, 2013.

Docência com profissionalidade. Brazilian Geographical Journal: Geosciences and Humanities research medium, v. 4, Special Issue 1, p. 38-49, Ituiutaba, Minas Gerais, 2013.

GIL, Antonio Carlos. Didática do ensino superior. São Paulo: Atlas 2007.

IMBERNÓN, F. La formación y el desarrollo profesional del profesorado. Hacia una nueva cultura profesional. Barcelona: Editorial Graó, 1998.

MASETTO, Marcos T. Competência pedagógica do professor universitário. 2. ed. São Paulo: Summus, 2012.

O Professor na Hora da Verdade: A Prática Docente no Ensino Superior. São Paulo: Editora Avercamp, 2010.

PERRENOUD, P. Dez competências para Ensinar. Porto Alegre: Artmed, 2000.

TORRE, Saturnino de la (Director): Estratégias Didácticas en el aula - Buscando la calidad y la innovación. Madrid: Editora UNED, 2008.

ZABALZA, Miguel A. Competencias docentes del profesorado universitário - Calidad y desarollo professional. Madrid: Ediciones de Narcea S.A, 2006.

RECEBIDO EM: 22/02/2016

APROVADO EM: 25/02/2016 